\title{
A Busca de Soluções para o Problema das Heparinas no Mercado Nacional
}

\author{
Walter J. Gomes', Domingo M. Braile ${ }^{2}$
}

$E^{2}$ m 2008, o mercado mundial enfrentou um período conturbado com relação à confiabilidade do produto heparina. Nos Estados Unidos e na Europa, lotes de heparina não-fracionada apresentaram contaminação fraudulenta e deliberada com a condroitina hipersulfatada, que resultaram em morte de centenas de pacientes. O Brasil também foi assolado pelo problema da heparina, mas de outra forma.

No início de 2008, após a retirada abrupta do mercado da heparina não-fracionada endovenosa do laboratório Roche (Liquemine), a Sociedade Brasileira de Cirurgia Cardiovascular (SBCCV) começou a receber alarmante aumento de consultas de cirurgiões cardíacos de todo o País, relatando o aparecimento de complicações com a utilização de outras marcas de heparina disponíveis no mercado nacional. Essas complicações reportadas envolveram principalmente aumento de sangramento pós-operatório e aparecimento de síndrome vasoplégica.

A mobilização da SBCCV começou pelo contato com o laboratório Roche, que reafirmou a decisão de cessar a produção do Liquemine endovenoso. Essa marca de heparina (produzida a partir da mucosa do intestino de suínos) era utilizada pela quase totalidade dos Serviços de Cirurgia Cardiovascular do País e apresentava grande confiabilidade. Ao mesmo tempo, a Agência Nacional de Vigilância Sanitária (ANVISA) foi notificada e as providências cabíveis, solicitadas.

Em seguida, a SBCCV procurou diretamente as companhias farmacêuticas que comercializam a heparina sódica não-fracionada no Brasil. Os laboratórios Eurofarma e Bérgamo produzem heparina sódica injetável a partir de matéria-prima (mucosa de intestino bovino) fornecida por empresas nacionais.

A análise desses produtos, realizada no Laboratório de Tecido Conjuntivo da Universidade Federal do
Rio de Janeiro, e testes adicionais realizados nos laboratórios da Universidade Federal do Paraná e da Universidade Federal de Santa Maria, no Rio Grande do Sul, mostraram não haver evidência de contaminação pela condroitina hipersulfatada no produto analisado. Também se observou que a quantidade de heparina de baixo peso molecular estava de acordo com o produto de referência.

Entretanto, com base nessas análises, evidenciouse clara diferença de potência de ação entre as heparinas não-fracionadas de origem bovina e as de origem suína, que era o caso do Liquemine. As heparinas suínas têm maior potência de ação que as bovinas, havendo necessidade de reajuste de dose e monitorização mais acurada quando da mudança do produto, o que ajuda a explicar as complicações observadas na ocasião da retirada do Liquemine do mercado.

Ficou patente que, embora seguras para uso, as heparinas fabricadas a partir de intestino bovino não são a escolha ideal para a cirurgia cardiovascular, ao contrário daquelas produzidas com intestino suíno. Houve recomendação da SBCCV para que, em decorrência da diferença de potência entre as heparinas não-fracionadas de origem tanto bovina como suína, se procedesse à utilização mais rigorosa dos testes de tempo de coagulação ativada (TCA) durante as cirurgias cardíacas, para assegurar que os níveis ideais de anticoagulação estivessem sendo alcançados.

Foi acordado que as companhias farmacêuticas, com o apoio da ANVISA e da SBCCV, passariam a desenvolver a heparina derivada de mucosa de intestino suíno, similar ao produto Liquemine retirado do mercado. Quatro companhias farmacêuticas nacionais - Blausiegel, Bérgamo, Eurofarma e Cristália - desenvolveram o produto heparina, derivado de intestino suíno. Nos testes de qualidade, essas heparinas suínas

\footnotetext{
1 Escola Paulista de Medicina, Universidade Federal de São Paulo - São Paulo, SP, Brasil.

2 Faculdade de Medicina de São José do Rio Preto - São José do Rio Preto, SP, Brasil e Universidade Estadual de Campinas - Campinas, SP, Brasil.

Correspondência: Walter J. Gomes. Rua Borges Lagoa, 1080/608 - São Paulo, SP, Brasil - CEP 04038-002

E-mail: wjgomes.dcir@epm.br

Recebido em: 8/5/2009 • Aceito em: 11/5/2009
} 
apresentaram estrutura química e atividade similares às do produto Liquemine, conforme estudo realizado no Laboratório de Tecido Conjuntivo da Universidade Federal do Rio de Janeiro, já que a matéria-prima para as indústrias nacionais vem da mesma companhia farmacêutica chinesa que fornecia para a empresa Roche. As farmacêuticas chinesas foram vistoriadas pelo Food and Drug Administration (FDA) e pela ANVISA, que deram aos laboratórios o certificado de Good Manufacturing Practices (GMP) e Boas Práticas de Fabricação (BPF), respectivamente.

Após longo e detalhado entendimento com a ANVISA e as empresas farmacêuticas nacionais que comercializam a heparina no Brasil, a SBCCV iniciou o estudo clínico com essas heparinas de origem suína a serem comercializadas no Brasil, com um protocolo extensivamente discutido entre essas partes, para assegurar a qualidade e a padronização do produto a ser colocado no mercado nacional.

O estudo clínico iniciado está sendo realizado em centro único para assegurar uniformidade de procedimento (Universidade Estadual de Campinas - UNICAMP) e vai fornecer informações clínicas e científicas relevantes para o conhecimento da ação dos produtos, assim como de sua neutralização pela protamina. É um estudo de fase III, cujo objetivo primário é verificar, por meio de estudo randomizado, aberto, paralelo e comparativo, a eficácia e a segurança da heparina sódica, não-fracionada, de origem suína, em pacientes submetidos a cirurgia cardíaca com auxílio de circulação extracorpórea, pelo controle da hemostasia durante e após o procedimento cirúrgico, baseado nas dosagens dos marcadores de coagulação, como TCA, tempo de tromboplastina parcial ativada (TTPa) e fator antiXa, na heparina biodisponível e na perda sanguínea. O objetivo secundário desse estudo é avaliar a dose média de heparina sódica utilizada nas cirurgias e sua relação com a dose de protamina e a necessidade de transfusões de sangue e hemoderivados, durante e após o procedimento. Também é objetivo secundário desse estudo avaliar a segurança do uso da heparina em relação a tipo, incidência e frequência de eventos adversos observados durante o período de estudo.
Em acordo estabelecido com a Fundação Adib Jatene, os aparelhos para mensuração do TCA e o substrato usado nos mesmos serão também avaliados para que possamos ter uma comparação adequada entre métodos avançados da avaliação da anticoagulação e da coagulação e o método simples (TCA) rotineiramente usado nas operações com circulação extracorpórea nos hospitais brasileiros.

Finalmente, a SBCCV gostaria de destacar o senso de responsabilidade e o profissionalismo demonstrado pelas empresas farmacêuticas nacionais, que empreenderam todos os esforços para desenvolver e suprir o mercado nacional com heparinas suínas não-fracionadas para uso específico na cirurgia cardiovascular, eliminando o grave problema deixado pela retirada do mercado do produto Liquemine da empresa Roche. Além disso, a ação da ANVISA, com profissionais competentes e dedicados e trabalhando em estreita colaboração com a SBCCV e a indústria nacional, promoveu as condições para o rápido restabelecimento do produto no mercado. Salientamos, também, a grande acolhida que a SBCCV teve por parte da ANVISA, que depositou toda a confiança em nossa Sociedade para que o protocolo fosse desenvolvido e implementado, mostrando uma parceria que certamente será benéfica não só nesse campo das heparinas como em outros em que a SBCCV, como lídima representante dos cirurgiões cardiovasculares brasileiros, poderá auxiliar na qualificação de todos os insumos por nós utilizados.

\section{CONFLITO DE INTERESSES}

Os autores declararam inexistência de conflito de interesses.

\section{REFERÊNCIA BIBLIOGRÁFICA}

1. Melo El, Pereira MS, Cunha RS, Sá MPL, Mourão PAS. Controle da qualidade das preparações de heparina disponíveis no Brasil: implicações na cirurgia cardiovascular. Rev Bras Cir Cardiovasc. 2008;23(2):169-74.

Texto publicado simultaneamente na Revista Brasileira de Cirurgia Cardiovascular, volume 24, fascículo 2, abril/junho de 2009. 